\title{
Exploring the views of being a proxy from the perspective of unpaid carers and paid carers: developing a proxy version of the Adult Social Care Outcomes Toolkit (ASCOT)
}

\author{
James Caiels ${ }^{1 *} \mathbb{D}$, Stacey Rand ${ }^{1}$, Tanya Crowther ${ }^{1,2}$, Grace Collins ${ }^{1}$ and Julien Forder ${ }^{1}$
}

\begin{abstract}
Background: Outcomes-based policy and administration of public services present a compelling argument for the value of outcomes data. However, there are a number of challenges inherent in collecting these data from people who are unable to complete a paper-based survey or interview due to cognitive or communication impairments. In this paper, we explore the views of being a proxy from the perspective of unpaid carers and paid carers who may be asked to act as a proxy on behalf of the person(s) they care for. We consider the key issues that need to be addressed when adapting an instrument designed to measure social care outcomes, the Adult Social Care Outcomes Tool (ASCOT), into a proxy-report tool.
\end{abstract}

Methods: Participants took part in either a focus group (35 paid carers in eight focus groups), or a one-to-one interview (eight unpaid carers). All participants were recruited via carer organisations and care providers. Transcripts, field notes and audio data collected during focus groups and interviews were analysed using a thematic framework approach.

Results: Participants agreed that any person acting as a proxy would need to be very familiar with the care recipient, as well as their needs and care provision. A number of provisions for proxy respondents were proposed to improve face validity and acceptability of completing a questionnaire by proxy, and to ensure that any potential bias is reduced in the design of the questionnaire. These included: providing two sets of response options for each proxy perspective (the proxy themselves and the proxy view of how they think the care recipient would respond); a comments box to help people explain why they have selected a given response option (especially where these indicate unmet need); and providing clear guidance for the proxy respondent on how they should complete the questionnaire.

Conclusions: This study has shown some of the challenges involved in assessing outcomes by proxy and explored some potential ways these can be mitigated. The findings highlight the benefits of developing and testing proxy measures in a robust way to widen participation in social care research.

Keywords: Quality of life, Social care, Outcomes, ASCOT, Proxy

\footnotetext{
* Correspondence: j.caiels@kent.ac.uk

${ }^{1}$ Quality and Outcomes of person-centred care policy Research Unit (QORU),

PSSRU Kent, University of Kent, Cornwallis Building, Canterbury CT2 7NF, UK

Full list of author information is available at the end of the article
}

(c) The Author(s). 2019 Open Access This article is distributed under the terms of the Creative Commons Attribution 4.0 International License (http://creativecommons.org/licenses/by/4.0/), which permits unrestricted use, distribution, and reproduction in any medium, provided you give appropriate credit to the original author(s) and the source, provide a link to the Creative Commons license, and indicate if changes were made. The Creative Commons Public Domain Dedication waiver (http://creativecommons.org/publicdomain/zero/1.0/) applies to the data made available in this article, unless otherwise stated. 


\section{Background}

The use of self-reported outcomes in evaluating public services has become more prevalent in recent times [1], while utilising outcomes data has become increasingly important in policy-based decision making in the UK [2]. In part, its purpose is to make public services more accountable to the people that use them. The mechanism applied, points stakeholders involved in care provision toward concentrating on the principle aim of providing services - to improve people's outcomes. In addition, identifying common factors in 'good' provision of public services can potentially be shared and applied to other provider settings. This outcomes-based approach has influenced different public services, including publicly-funded social care. (Social care refers to a range of different long-term care services for people with physical or intellectual disabilities, mental health problems, frailty, or impairments due to older age: for example, day care, home care or residential care).

Since social care interventions aim to support people to maintain or improve their quality of life, the quality of life of the person who receives support has been identified as a key outcome of the quality and effectiveness of social care [3-7]. In the UK, social care policy strategy has identified the quality of life of people with support needs as an overarching indicator of the performance of the social care sector [8]. A measure of social care-related quality of life, and the focus of this paper, is the Adult Social Care Outcomes Toolkit (ASCOT) [9, 10]. The ASCOT is a measure designed for self-completion by social care service users, regardless of the reason(s) why they need social care support. It is included as an overarching outcome measure in the Adult Social Care Outcomes Framework (ASCOF) for England, which seeks to provide an overview of national and local performance that promotes transparency, accountability and service improvement driven by the needs of people who use services [11]. The ASCOT questionnaire includes eight items for each of the following social care-related quality of life attributes: Control over daily life; Occupation ('doing things I value and enjoy'); Social participation and involvement; Personal safety; Personal cleanliness and comfort; Food and drink; Accommodation cleanliness and comfort; and Dignity (www.pssru.ac.uk/ascot) [10]. Each attribute is rated by self-report as the ideal state, no needs, some needs or high-level needs [10]. In England, the ASCOT has been used to evaluate and inform policy strategy, commissioning and care practice [11-15]. Table 1 shows the ASCOT domains and definitions.

While the rhetoric of outcomes-based policy and administration of public services presents a compelling argument for the value of outcomes data, there are challenges associated with its measurement, collection and application [1, 2]. The use of patient-reported outcome measures in the evaluation of healthcare interventions also share many of these challenges. In this paper, we consider the measurement challenge of how to collect information from people who are unable to complete a paper-based survey or interview, even with adaptations or adapted questionnaire formats, due to cognitive or communication impairments. Specifically, we focus on people with intellectual disability and/or autism, dementia or other age-related cognitive or communication impairments. The systematic exclusion of people who are unable to self-report their quality of life may contribute to issues of sample size, missing data, bias, equity and inclusion in the context of the evaluation of health and social care interventions [16, 17]. In the application of quality of life data to an outcomes-based approach that seeks to give people an active voice in shaping the public services they use, the issues of equity and inclusion are especially important.

Table 1 ASCOT domains and definitions

\begin{tabular}{|c|c|}
\hline Control over daily life & The respondent is able to choose what to do and when to do it, having control over daily life and activities. \\
\hline $\begin{array}{l}\text { Personal cleanliness } \\
\text { and comfort }\end{array}$ & $\begin{array}{l}\text { The respondent feels personally clean and comfortable and looks presentable. At best, is dressed and groomed } \\
\text { in a way that reflects personal preferences. }\end{array}$ \\
\hline Food and drink & $\begin{array}{l}\text { The respondent feels that s/he has a nutritious, varied and culturally appropriate diet with enough food and drink, } \\
\text { at regular and timely intervals, that he/she enjoys. }\end{array}$ \\
\hline Personal safety & $\begin{array}{l}\text { The respondent feels safe and secure. This means being free from fear of abuse, falling or other physical harm and } \\
\text { fear of being attacked or robbed. }\end{array}$ \\
\hline $\begin{array}{l}\text { Social participation } \\
\text { and involvement }\end{array}$ & $\begin{array}{l}\text { The respondent feels content with his/her social situation, where social situation is taken to mean the sustenance } \\
\text { of meaningful relationships with friends and family, and feeling involved or part of a community, should this } \\
\text { be important to the service user. }\end{array}$ \\
\hline Occupation & $\begin{array}{l}\text { The respondent is sufficiently occupied in a range of meaningful activities whether it be formal employment, } \\
\text { unpaid work, caring for others or leisure activities. }\end{array}$ \\
\hline $\begin{array}{l}\text { Accomodation cleanliness } \\
\text { and comfort }\end{array}$ & The respondent feels that the home environment, including all rooms, is clean and comfortable. \\
\hline Dignity & $\begin{array}{l}\text { The psychological impact of the way support and care services are provided on the service user's personal sense } \\
\text { of significance and sense-of-self. }\end{array}$ \\
\hline
\end{tabular}


The use of proxy respondents is one potential solution to this problem and is commonly used in health research. A proxy is an individual who reports on behalf of a study participant. Proxy report, however, also presents a number of measurement-related challenges. Although studies that compare proxy-report to self-report may not extrapolate to cases where the individual is unable to self-report, there is evidence that proxy respondents systematically underestimate quality of life compared to self-report (for example, in studies of people with dementia [18-36], stroke [37-39] or intellectual disabilities $[40,41])$. This difference between proxy- and self-report has been found to be related to various factors: for example, the measurement properties of the instrument, whether the attributes are 'objective' or 'subjective', the study's sample size, the proxy's level of literacy, whether the proxy experiences depression or pain, and the nature and closeness of the relationship between the proxy and the individual [21, 42]. There is also evidence that proxy-rating of quality of life may vary by whether the proxy answers are based on their own view (proxy-proxy perspective) or the proxy's internal reconstruction of what that individual may think (proxy-patient perspective), which may introduce bias if it is not considered in the presentation and wording of items [43-45].

A further consideration is whether proxy-report may inadvertently contribute to the issue of the exclusion of individuals with cognitive and communication impairments from health and social care research it is designed to address. The inappropriate use of proxy report when data collection by self-report is feasible (for example, using alternative formats such as easy-read) would contribute to the exclusion of people from 'having a voice'. Despite these challenges with proxy-report, however, it may be argued that proxy-report is preferred to systematic exclusion of people who are unable to self-report quality of life $[16,17]$.

Although proxy-report is widely-used, it is notable that many quality of life instruments completed by proxy were not specifically developed as proxy-report instruments. Also, little is known about the acceptability of care-related quality of life data collection to paid or unpaid paid carers acting as proxy respondents on behalf of adults with social care support needs. While it may be argued that adaptation of standard self-completion questionnaires may enhance their acceptability and face validity for use with proxies (for example, incorporating comments boxes for proxy respondents to complete), proxy-report instruments are typically adapted and developed from self-report measures without qualitative evidence from potential proxy respondents [46].

This study is a qualitative study to identify and explore the key issues associated with acting as a proxy to report care-related quality of life from the perspective of potential proxy respondents. We wanted to explore the perceived challenges of acting as a proxy respondent, and what kinds of adaptations might mitigate these difficulties. Although others may act as proxy respondents for example, advocates, volunteers or health care professionals - we explored the views of being a proxy from the perspective of unpaid carers and paid carers who may be asked to act as a proxy on behalf of the person(s) they care for. We aimed to assess the significance of the issues outlined above when using proxies and in turn the implications for adapting an instrument designed to measure social care outcomes, specifically the ASCOT, into a proxy-report tool. In doing this, we wanted to explore the feasibility of developing a proxy version for people with intellectual, cognitive and/or communication impairments and identify what form any adaptations may take.

\section{Methods \\ Design}

We took an inductive approach led by participants, seeking to elicit views about the challenges associated with acting as a proxy. Participants took part in either a focus group (paid carers) or a one-to-one interview (unpaid carers). This approach was primarily pragmatic to gain access to participants. Initial attempts to arrange focus groups or one-to-one interviews with all participants proved challenging due to individual circumstances and commitments. Paid carers were more able to participate in a focus group at a central office after shifts, and arranging one-to-one interviews with unpaid carers in their own homes was far more convenient to accommodate their own schedule. Both groups were presented information in the same way to maintain consistency.

Participants in focus groups and interviews were shown the ASCOT self-completion (SCT4) questionnaire. This was not adapted in any way for proxy-use beforehand. Using a topic guide designed for this study (Additional file 1), participants were asked to comment on the questions, to think about them in relation to a (or the) person they care for, as well as consider how being a proxy might affect their response to the questions, and what adaptations would be necessary for proxy use (see Fig. 1). The ASCOT domains were presented to participants one at a time.

\section{Recruitment}

\section{Focus groups with paid carers}

Paid carers were recruited to the study by contacting a randomly-selected sample of domiciliary care providers in Kent and Medway. Following initial contact with 121 care providers, individual recruitment packs with information sheets and consent forms were sent to four care providers that responded and were willing to take part. In total, 35 paid carers volunteered to participate. 


$$
\begin{aligned}
& \text { Why would you give that answer? } \\
& \text { What would you/are you thinking about when you answer it? } \\
& \text { Would you feel comfortable answering on someone else's behalf? } \\
& \text { Do you think you would have a different opinion to them? }
\end{aligned}
$$

Fig. 1 Excerpt from topic guide for focus groups and interviews

Eight focus groups were conducted on premises belonging to the organisations, at their request, with between two and eight participants in each.

Focus groups lasted between 75 and $90 \mathrm{~min}$ and each covered three or four of the eight domains of the ASCOT SCRQoL indicator. Each domain was tested a minimum of three times across the eight groups. It was not possible to present all eight domains in each group due to time constraints. Seven focus groups were recorded and transcribed verbatim, with participants' consent. One focus group was not recorded at the request of participants; in this case, detailed notes were made.

\section{Interviews with unpaid carers}

A total of eight unpaid carers were recruited via carer organisations and care providers. In addition, advertisements were placed on a University Adult Research Unit mailing list and on the University staff intranet. Interviews took place in a location convenient for each interviewee, either the respondent's home $(n=6)$ or university premises $(n=2)$.

Participants provided varying levels and types of care, although all could comment on the ASCOT attributes. Interviews lasted between 45 and $60 \mathrm{~min}$ and covered between three and eight SCRQoL attributes. All eight interviews were recorded and transcribed verbatim.

\section{Analysis}

Transcripts, field notes and audio data collected during focus groups and interviews were transferred to NVivo 10 for analysis using a framework approach [47, 48]. Framework analysis is a method for thematic analysis of qualitative data that follows a systematic series of distinct steps: transcription; familiarisation with the data; initial coding; developing an analytical framework by identifying recurrent and important themes; applying the analytical framework by indexing existing codes; charting data into a framework matrix; and interpreting the data [49]. In this study, the audio recordings from interviews and focus groups were transcribed verbatim. Two researchers (TC, JC) familiarised themselves with the transcripts, audio recordings and interview notes in order to identify key ideas and recurrent themes. Some themes were pre-defined, having been identified in the literature as potentially key issues for proxy respondents: for example, the different perspectives that proxies may adopt to answer proxy-report questions, and the acceptability of being a proxy $[46,50]$. Other themes emerged through the data. The thematic framework, or index, was agreed by the researchers (JC, TC) and applied to the data. The process of coding and interpretation was influenced by the original research objective, as well as by the themes that emerged from the data. Two focus groups and two interviews were coded by both researchers. Any differences were discussed until a consensus was reached. Any subsequent cases where coding was uncertain were also discussed until consensus was reached. In the final step, we examined the range and nature of experiences and looked for associations between themes to explore explanations and practical implications.

\section{Ethics}

The study was reviewed and approved by the national Social Care Research Ethics Committee (SCREC) in England (now as per the NHS Health Research Authority (HRA) process) (reference: 13/IEC08/0020). Written informed consent was obtained from all participants prior to interview or focus group.

\section{Results}

A total of 43 participants took part, with a mean age of 42 years (range 19 to 78 years). Of these, 35 were female and eight were male. Forty-one participants described their ethnicity as white British. All participants reported caring for someone with an intellectual disability and/or autism and/or dementia and/or communication or cognitive impairments related to older age (see Table 2 below).

A number of themes emerged from the process of conducting focus groups and interviews with paid carers and unpaid carers. Those covered in this paper include: being a proxy; who can/should be a proxy; thinking and 
Table 2 Characteristics of care-recipients known to the proxy respondents

\begin{tabular}{lll}
\hline & Overall Sample \\
\cline { 2 - 3 } & $\mathrm{N}(=43)$ & $\%$ \\
\hline Intellectual disability and/or autism & 24 & 56 \\
Intellectual disability and/or autism & 10 & 23 \\
and/or dementia or Alzheimer's & & \\
Dementia or Alzheimer's & 5 & 12 \\
Age-related impairments & 4 & 9 \\
\hline
\end{tabular}

feeling on someone's behalf; elaborating and justifying answers; differing responses; perceived impact of need and receiving care; and answering in context.

\section{Being a proxy}

The concept of acting as a proxy was initially challenging for paid carers. Almost all paid carers reported having difficulty with the idea of answering questions on someone's behalf, particularly when related to receiving social care services. Many reflected on their own training and how this encouraged and stipulated that all aspects of care given should actively include the care recipient as far as this was possible. Acting as a proxy appeared to be counter to that: "I mean I wouldn't personally complete this for anybody...not if they couldn't provide me with any input at all I couldn't, and I wouldn't advise any other staff to either" (paid carer).

By contrast, all unpaid carers were comfortable with adopting the proxy role. Unpaid carers largely saw this as an extension of their caring responsibilities where people were not able to answer for themselves: "it's got to be people in my position who answer on their behalf" (unpaid carer). This level of comfort and ease with the idea of being a proxy, and answering on behalf of somebody else, appeared to stem from the nature of the relationship between the proxy and cared-for person (i.e. professional/client or family relationship). Because of this, unpaid carers could draw on their knowledge of the cared-for person and, in the case of people receiving care due to progressive disease, reflect on what had been their personal preferences prior to receiving care. This appeared to create added comfort in the proxy role for unpaid carers, and confidence that responses would be an accurate reflection of the cared for person's view.

"Yeah. Again, because I see them regularly and I speak to them daily, in my situation I feel that I know them quite well so I could quite easily go, yeah, that's where she would tick sort of thing." (unpaid carer).

\section{Who can/should to be a proxy?}

A critical question about using proxy respondents is who should or can act as a proxy for someone else. All respondents (paid and unpaid carers) agreed that whoever is acting as a proxy by answering questions on behalf of someone else should know that person well and be familiar with their care needs and the services that they use: "You'd have to make sure that the person that knew that individual the most and worked with them would complete the document, wouldn't you" (paid carer). Even where this was the case, some carers felt they might not be able to comment on all aspects of a person's quality of life. This would depend on a number of factors, such as the client's specific needs or experience of living with a long-term condition, the nature and quality of the carer's relationship with the cared-for person and the proximity of the interview to events like falls or issues with quality of care.

\section{Thinking and feeling on someone's behalf}

One major difficulty reported by all (paid and unpaid) carers was being required to answer questions about how the care recipient would think or feel about certain aspects of their lives. This was particularly the case for those domains that relate to abstract concepts (i.e. dignity, occupation, control over daily life).

\section{"I don't think anyone would feel comfortable either trying to guess how someone feels, because I think you'd feel a bit like that's my opinion, do you know what I mean, like, and I don't know if I would feel right saying that's how they feel sort of thing 'cause I don't really know, I can guess because obviously you do have a good relationship with them and you probably do get the gist of what they would feel, but I don't know if I'd want to put my name to that sort of thing, do you know what I mean?" (paid carer).}

Interestingly, regardless of domain, the ASCOT questions relate to subjective experience rated by the extent to which individual needs and preferences are met. Nonetheless, questions based around more 'tangible' aspects of lives, such as food and drink, were generally considered less problematic.

\section{Elaborating and justifying answers}

When considering what would help or encourage carers to answer questions as a proxy, almost all paid carers were in favour of the idea of providing an additional (optional) comments box. The purpose of this would be for proxy respondents to give additional information to the response they had chosen that they felt was relevant. Paid carers expressed that this would be particularly important in cases where the response they had chosen was towards the lower end of the scale (worst outcome states). In these cases, paid carers viewed a comments box as being essential in order to feel comfortable in answering. Paid carers envisaged using the comments box 
to provide further information to explain and justify their response. There was particular concern among paid carers that a bottom-level response would reflect badly on themselves, when in fact there was a 'legitimate' reason that they answered at this level. This could be, for example, a condition-specific behaviour that led to being unclean rather than being an indication of neglect or lack of care provision.

"I think a massive thing that would be brilliant for, if it's for people like us, always have comment boxes, always, like, 'cause like you were just saying, like if you were to tick like I don't feel at all clean and presentable, at least you'd feel a bit like, I can write why" (paid carer).

Paid carers expressed the fear that answering negatively may result in being reprimanded or even losing their jobs. As a result, while none of the participants stated that they would deliberately answer dishonestly, this was identified as a potential issue. Almost all paid carers agreed that the provision of a comments box would allay this fear and encourage paid carers to be open and honest when answering. By contrast, unpaid carers suggested that some people may intentionally choose high needs (less positive answers) in the hope of improving services for the person they cared for. All unpaid carers though, were also in favour of a comments box in order to elaborate answers and provide more detail to justify responses.

\section{Differing responses}

Participants reported that a major challenge of completing a questionnaire as a proxy respondent is the potential difference between how they (the carer) would respond compared to how they think the cared-for person would respond. Reasons for this include differences in personal preference, the impact of the long-term condition on an individual's behaviour, cognition, and sense of self. An example of this was seen in the accommodation comfort and cleanliness domain, where one person's idea of 'clean and comfortable' may differ from another's because of differing standards and preferences.

"All I would say with some of these questions, is that they could be seen different by different people, because everyone's got different standards of cleanliness. You've got people that over-tidy and then might say actually my house is not tidy, but it is, or it might be the other way" (paid carer).

Many participants, and in particular paid carers, felt that responses to the items on accommodation or personal cleanliness and food/drink would be influenced by their own views and attitudes towards how clean or tidy they keep their own house, their own preferred frequency of bathing and standards of personal hygiene, the types of food they like to eat, and so on. There was a feeling of unease in responding to questions where participants thought that their own and the cared-for person's view, attitudes and preferences would be different. A potential solution proposed by the study participants was to include two sets of response options: one for 'how I think this person would answer' and another for 'my opinion'. This was supported particularly by paid carers as a way of alleviating any concerns they had, and provided a way of expressing both perspectives.

Striking a balance between encouraging someone to make their own choices and have control over their life, against being responsible for that person's health and wellbeing, was also something that paid carers in particular found challenging when choosing a response. For example, one paid carer explained that the person they cared for would have an extremely unhealthy and inappropriate diet if they did not help them make some healthy food choices. While it may not be what the person wanted, the carer felt it was their responsibility to manage diet and to avoid unhealthy foods. However, in considering how the person they were answering for may feel about this, paid carers considered whether this may feel like a lack of control for the person being cared for, because they were stopping someone from doing something they would otherwise choose to do. Paid carers explained that this was well-intentioned on their part and part of their responsibility as carers, but may still result in these feelings on the part of the person being cared for. Approximately half of unpaid carers also pointed to this (striking a balance) as a potential difficulty when answering the 'control over daily life' domain question. Almost all carers (paid and unpaid) stated that having two sets of response options would allow this to be reflected in responses.

\section{"He would go and sit in Tesco and eat every caramel bar and drink every bottle of Dr Pepper in there until it was all cleared out, but that isn't going to be very good for his health so I can't let him do that. But then he'd probably say 'I'm not getting all the food and drink that I want', because he's got this obsession" (paid carer).}

\section{Perceived impact of need and receiving care}

For some carers the very nature of being a care recipient negated being able to choose the top-level responses. Primarily this was for the 'higher-level' domains of control over daily life, dignity, and occupation, although for paid carers it was exclusive to the control over daily life domain. A number of paid carers argued that an 
individual cannot possibly have 'as much control as they want' (the 'ideal state' for the ASCOT control domain) if they are in receipt of social care services. This was predicated on the assumption that the need for any help immediately discounted the prospect of responding at the top level. ASCOT works on the principle that this is feasible due to the adaptation of an individual's perspective, attitude and preferences to their personal circumstances. This view was not shared by all paid carers, while two unpaid carers also held this view.

"I think as soon as you have care then it's got to be I have adequate control over my life, because as soon as you're having somebody come into your home, you know, you're having to ask somebody else to do something for you at a set time, so they can't--, they haven't got complete control over their life" (paid carer).

For two unpaid carers this also applied to the dignity domain, where people felt that the need for care, particularly personal care, immediately discounted the top-level response option. Again, this was based on the idea that a person 'cannot have dignity' if they require help with personal care: "How can you be dignified if somebody else is wiping your bum? Sorry, but, you know, there's nothing dignified in some of the things, is there, so it's really not" (unpaid carer).

\section{Answering in context}

For some unpaid carers, timing was an important factor in how they would potentially answer. Answers may differ depending on context and what had been happening recently. Unpaid carers that identified this as a potential difficulty suggested that some guidance around the time-frame to think about when considering responses would help. When asked what period this should cover, 3 months was considered a reasonable time to reflect on.

A number of unpaid carers explained that thinking about other variables also made it difficult to aggregate in order to choose a single response. These included: which service should people be thinking about; the different aspects of domains, such as being inside or outside the home for safety; and varying levels of occupation depending on different days or different activities.

There was some concern around underestimating the impact of services, or indeed their own caring role. Participants wanted it to be clear that current quality of life was only being achieved because of the role that either paid or unpaid care played in the person's wellbeing.
"I would say 'I get all the food and drink I like when I want', but I think that gives a false impression, you know, that's what I felt before [with previous questions], that it's always going to give a false impression because he only gets it because there's somebody there to give it to him, you know, otherwise he wouldn't get anything" (unpaid carer).

\section{Discussion}

This qualitative study sought to identify and explore key challenges with rating ASCOT social care-related quality of life on behalf of someone else from the perspective of two groups of proxy respondents: paid carers and unpaid carers. We aimed to assess how, given the issues identified, quality-of-life instruments might be adapted for proxy use. We argue that 'framing questions' in a proxy instrument may help to reduce bias that can arise from respondents systematically adopting different proxy perspectives in formulating their response, and improve the acceptability of the instrument to proxy respondents. In particular, we propose that proxy questionnaires should have the following features: (1) providing two sets of response options for each proxy perspective (one for the proxy's own view and one from the proxy's view of what they think the care recipient would answer if they were able to); (2) adding comments boxes to help people explain why they have selected a given response option (especially where these indicate unmet need); (3) clearly identifying the role of the proxy respondent (paid or unpaid carer), including their relationship with the care recipient; and (4) providing clear guidance setting out exactly what is expected of the proxy respondent and how they should complete the questionnaire. As to the latter, this might include specific commitments that individuals' responses would be anonymised and not linked specifically to service eligibility/assessment for individuals. We outline how we subsequently embedded these features into a proxy version of the ASCOT measure in a separate paper [51].

Some respondents, especially paid carers, expressed reservations about answering social care-related quality of life questions on someone else's behalf. The ASCOT items all relate to subjective quality of life attributes rated against the individual's preferred 'ideal state'. In particular, it was noted that questions that relate to abstract areas of life that may not be directly observed were described as most difficult for the respondents to judge and respond to. Attributes like food and drink, for example, may be rated based on the respondent's observations of the care recipient. In that case, the care recipient's internal subjective state could be extrapolated from observable cues taken from external behaviours and expressions. By contrast, the respondents found it more 
difficult to rate attributes like dignity, which is an internal mental construct (i.e. the psychological impact of how care is provided), for which there may be fewer or no observable external cues for the proxy respondent to draw upon. This finding is consistent with studies that have found a higher degree of agreement between proxy-report and self-report for observable quality of life attributes (e.g. physical mobility, self-care, usual activities) compared to non-observable or subjective attributes (e.g. pain, anxiety, depression, family relationships) $[17,25,40,52-58]$.

Both paid and unpaid carers identified and explored the issue of biased ratings of quality of life by proxy respondents. Paid carers who took part in focus groups suggested that, while they themselves would not do it, other 'unscrupulous' carers might intentionally give more positive responses to avoid ones that may reflect badly on their care practice. This was also identified as a potential issue by unpaid carers, albeit in reverse (that is, intentionally rating lower or more negative quality of life to prompt quality improvement or increased levels of support for the care recipient). Interestingly, while there is evidence from other studies that healthcare professionals rate proxy-reported quality of life higher than unpaid carers $[16,59-61]$, this difference may be due to the level of contact with and closeness to the care recipient rather than a reporting bias attributable to a difference between paid and unpaid carers per se [30,62]. The motivation to deliberately skew the overall quality of life score may be specific to data collections, such as the ASCS, which will be used to evaluate and inform policy strategy, commissioning, resource allocation or the practice of care.

Another theme identified by respondents was that proxy respondents felt that their own response would sometimes differ to how they thought the cared-for person would answer. Generally, this was either because: the proxy had differing standards or preferences (e.g. for cleanliness) from the person they were answering for; they felt happier expressing their own opinion rather than someone else's; or that, while the cared-for person may be happy with their care provision, the proxy respondent felt improvements could be made. This difficulty may stem from uncertainty around which perspective proxy respondents should adopt in the absence of instructions (that is, should they report what they think the individual would respond ('proxy-patient' perspective) or their own view of the individual's quality of life ('proxy-proxy' perspective) [45]). Giving detailed guidance in the instructions to the proxy respondent may go some way to addressing this issue.

The findings presented here suggest that the acceptability' of being a proxy (to the proxy) is dependent on their relationship with the cared for person and having knowledge of their needs and preferences. One implication of the findings is that while both proxy views should be regarded as valid (proxy-proxy and proxy-patient), it should be made clear which view you are asking for (collecting) and then subsequently analysing and presenting. Another implication is that we might expect less reliable answers from proxies relating to the 'higher-order' domains of ASCOT, and this should be acknowledged in the analysis of proxy data. Moreover this suggests that more 'framing' adaption is required for questions relating to attributes of quality of life perceived to be 'less tangible'.

Interestingly, in social care data collections like the Adult Social Care Survey (ASCS) in England, only 5.9\% of proxy respondents were paid carers [63]. By comparison, over a third (36.8\%) of proxy respondents were friends or family co-resident with the service user. The majority of proxy respondents $(57.3 \%)$ were people outside of the household or residential home other than a paid carer. (These are most likely unpaid carers who are not co-resident with the care recipient but may include other groups: for example, advocates) [63]. This raises the question of whether the adaptation of a quality of life tool for proxy-report should seek to target the majority group of proxy respondents (that is, unpaid carers) or whether it should seek to improve engagement with paid carers as potential proxy respondents. At the very least, we should seek to identify who the proxy respondent is and be aware of the potential bias linked to different motivations of respondents.

While the non-equivalence of self-report and proxy report is acknowledged, some studies have found that the systematic difference between average self-reported and proxy-reported quality of life score is modest $[16,18,41,53$, 64-66] or not significant [55, 67-69]. In which case, if the development of a proxy version of a quality of life instrument was primarily motivated by the minimisation of 'proxy bias' or the reduction of the inter-proxy gap [45], it would be reasonable to question the usefulness of developing a proxy version if the inter-proxy gap is negligible in large survey data collections. In this study, however, we have identified that the development of an instrument adapted for completion by proxy respondents could address the reluctance to answer questions on behalf of somebody else, and also improve the face validity of the instrument and the acceptability of its use. This may also enable wider participation in data collection that may influence policy, planning and administration of social care services and enable individuals, who would otherwise be excluded, to have a voice.

The study has some limitations. Whilst the findings may be applicable to the use of proxy tools more generally, participants were asked specifically about their views of answering the ASCOT on behalf of a person they care for. A further limitation of this study is, therefore, that it did not consider proxy respondents other 
than paid and unpaid carers (for example, advocates or other third sector staff or volunteers).

\section{Conclusion}

This study has shown some of the challenges involved in assessing outcomes by proxy and also explored some potential ways these can be mitigated. The approach was to explore the views of paid carers and unpaid carers. Participants acknowledged some of the difficulties they faced as a proxy respondent, such as whose perspective they were being asked to provide (their own or that of the care recipient) and outlined the potential impact of differing proxy perspectives and motivations, which could lead to bias. Participants described having greater difficulty answering questions that were perceived to be 'more abstract', such as dignity, than those perceived to have more tangible cues, such as whether someone had had food and drink.

We argue that specific proxy questionnaires should be developed that use various framing questions to help people minimise bias. A number of provisions for proxy respondents were proposed to improve face validity and acceptability of completing a proxy questionnaire (from the viewpoint of 'giving people a voice'); and to ensure that any potential bias is reduced in the design of the questionnaire. These included: providing two sets of response options for each proxy perspective (one for the proxy and from the view of the care recipient); a comments box to help people explain why they have selected a given response option (especially where these indicate unmet need); and providing clear guidance setting out exactly what is expected of the proxy respondent and how they should complete the questionnaire.

Moreover, both paid and unpaid carers agreed that any person acting as a proxy would need to be very familiar with the care recipient, as well as their needs and care provision. It would be important to record the relationship between the proxy and the care recipient in the proxy questionnaire.

The findings highlight the benefits of developing and testing proxy measures in a robust way (as opposed to making simple grammatical changes to a standard version) to widen participation in social care research.

\section{Additional files}

Additional file 1: Proxy Interview Schedule for carers Topic guide for interviews with carers, Interview guide used for data collection. (DOCX 19 kb)

\section{Abbreviations}

ASCOT: Adult Social Care Outcomes Toolkit; PROMs: Patient reported outcome measures; SCRQoL: Social care-related quality of life; SCT4: Selfcompletion, four-level questionnaire

\section{Acknowledgements}

We are very grateful to all who participated in the research and the organisations who supported recruitment of paid carers and unpaid carers.

\section{Funding}

The research on which this article is based is from independent research commissioned and funded by the Policy Research Programme at the Department of Health under the Quality and Outcomes of Person-Centred Care Research Unit (QORU). The research was peer reviewed by the Department of Health prior to taking place. The Department of Health had no role in the design of the study, the collection, analysis or interpretation of data. The Department of Health had no role in the writing of the manuscript. The views expressed are those of the authors and not necessarily those of the Department of Health.

\section{Availability of data and materials}

The dataset generated and analysed during the current study are not publicly available. This is because participants did not consent for the data collected to be made public or shared with any other parties. Participants did consent to the use of de-identified quotes as used in the manuscript. The ASCOT SCT4 was used in the study with the permission from the measure developer, the ASCOT team at the Personal Social Services Research Unit (PSSRU) (www.pssru.ac.uk/ascot), and the copyright holder - the University of Kent.

\section{Authors' contributions}

$J C$ designed the study, collected and analysed the data, and drafted the manuscript. SR contributed to the design of the study, collected and analysed the data, and contributed to the draft of the manuscript. TC contributed to the design of the study, collected and analysed the data, and contributed to the draft of the manuscript. GC contributed to the design of the study, collected and analysed the data, and contributed to the draft of the manuscript. JF contributed to the design of the study and the draft of the manuscript. All authors have read and approved the final manuscript.

\section{Ethics approval and consent to participate}

The study was reviewed and approved by the national Social Care Research Ethics committee in England (reference: 13/IEC08/0020). Written informed consent was obtained from all participants prior to interview or focus group.

\section{Consent for publication}

Written consent was sought and obtained from all participants.

\section{Competing interests}

The authors declare that they have no competing interests.

\section{Publisher's Note}

Springer Nature remains neutral with regard to jurisdictional claims in published maps and institutional affiliations.

\section{Author details}

'Quality and Outcomes of person-centred care policy Research Unit (QORU), PSSRU Kent, University of Kent, Cornwallis Building, Canterbury CT2 7NF, UK. ${ }^{2}$ NatCen Social Research, 35 Northampton Square, London EC1V OAX, UK.

Received: 29 March 2017 Accepted: 19 March 2019

Published online: 29 March 2019

References

1. Bovaird T, Loffler E. Evaluating the quality of public governance: indicators, models and methodologies. Int Rev Adm Sci. 2003;69(3):313-28.

2. Bovaird T. Attributing outcomes to social policy interventions: 'Gold standard' or 'Fool's gold' in public policy and management? Soc Policy Adm. 2014;48(1):1-23.

3. Netten A. Overview of outcome measurement for adults using social care services and support. London: National Institute for Health Research, School for Social Care Research; 2011.

4. Bamford C, Qureshi H, Nicholas E, Vernon A. Outcomes in community care practice. Outcomes for disabled people and carers. York: Social Policy Research Unit, University of York; 1999. 
5. Nocon A, Qureshi H. Outcomes of community care for users and carers: a social service perspective. London: Open University Press; 1996.

6. Nocon A, Qureshi H, Thornton P. Outcomes in community care practice: the perspectives of users' and carers' organisations. London: University of York: Social Policy Research Unit; 1997.

7. Qureshi H, Patmore C, Nichols E, Bamford C. Outcomes in community care practice. Overview: outcomes of social care for older people and carers. York: Social Policy Research Unit, University of York; 1998.

8. Department of Health. Transparency in outcomes: a framework for adult social care. London: Department of Health; 2010.

9. Malley J, Towers AM, Netten A, Brazier J, Forder J, Flynn T. An assessment of the construct validity of the ASCOT measure of social care-related quality of life with older people. Health Qual Life Outcomes. 2012;10:21.

10. Netten AP, Burge P, Malley J, Potoglou D, Towers AM, Brazier B, Flynn T, Wall B. Outcomes of social care for adults: developing a preferences weighted measure. Health Technol Assess. 2012;16(16):1.

11. Department of Health. The adult social care outcomes framework 2015/16 London: Department of Health; 2014.

12. Department of Health. Transparency in outcomes: a framework for quality in adult social care. The 2012/13 Adult social care outcomes framework. London: Department of Health; 2010.

13. Forder J, Jones K, Glendinning C, Caiels J, Welch E, Baxter K, Davidson J, Windle K, Irvine A, King D, Dolan P. Evaluation of the personal health budget pilot programme. Canterbury: PSSRU, University of Kent; 2012.

14. Johnstone L, Page C. Using Adult Social Care Outcomes Toolkit (ASCOT) in the assessment and review process. Res Policy Plann. 2013/14;30(3):179-92.

15. Heath C, Malley J, Razik K, Jones K, Forder J, Fox D, Caiels J, Beecham J. How can MAX help local authorities to use social care data to inform local policy? Canterbury: QORU, University of Kent; 2016.

16. Steel $\mathrm{J}$, Geller DA, Carr BI. Proxy ratings of health related quality of life in patients with hepatocellular carcinoma. Qual Life Res. 2005;14(4):1025-33.

17. von Essen L. Proxy ratings of patient quality of life - factors related to patient-proxy agreement. Acta Oncol. 2004;43(3):229-34.

18. Edelman P, Fulton BR, Kuhn D. Comparison of dementia-specific quality of life measures in adult day centers. Home Health Care Serv Q. 2004;23(1):25-42.

19. Sloane PD, Zimmerman S, Williams CS, Reed PS, Gill KS, Preisser JS. Evaluating the quality of life of long-term care residents with dementia. Gerontologist. 2005;45 Spec No 1(1):37-49.

20. Jonsson L, Andreasen N, Kilander L, Soininen H, Waldemar G, Nygaard H, Winblad B, Jonhagen ME, Hallikainen M, Wimo A. Patient- and proxyreported utility in Alzheimer disease using the EuroQoL. Alzheimer Dis Assoc Disord. 2006;20(1):49-55

21. Schiffczyk C, Romero B, Jonas C, Lahmeyer C, Muller F, Riepe MW. Generic quality of life assessment in dementia patients: a prospective cohort study. BMC Neurol. 2010;10:48

22. Naglie G, Tomlinson G, Tansey C, Irvine J, Ritvo P, Black SE, Freedman M, Silberfeld M, Krahn M. Utility-based quality of life measures in Alzheimer's disease. Qual Life Res. 2006;15(4):631-43.

23. Hoe J, Katona C, Orrell M, Livingston G. Quality of life in dementia: care recipient and caregiver perceptions of quality of life in dementia: the LASER-AD study. Int J Geriatr Psychiatry. 2007;22(10):1031-6.

24. Arlt S, Hornung J, Eichenlaub M, Jahn H, Bullinger M, Petersen C. The patient with dementia, the caregiver and the doctor: cognition, depression and quality of life from three perspectives. Int J Geriatr Psychiatry. 2008;23(6):604-10.

25. Huang HL, Chang MY, Tang JS, Chiu YC, Weng LC. Determinants of the discrepancy in patient- and caregiver-rated quality of life for persons with dementia. J Clin Nurs. 2009;18(22):3107-18.

26. Kunz S. Psychometric properties of the EQ-5D in a study of people with mild to moderate dementia. Qual Life Res. 2010;19(3):425-34.

27. Bruvik FK, Ulstein ID, Ranhoff AH, Engedal K. The quality of life of people with dementia and their family carers. Dement Geriatr Cogn Disord. 2012;34(1):7-14

28. Crespo M, Bernaldo de Quiros M, Gomez MM, Hornillos C. Quality of life of nursing home residents with dementia: a comparison of perspectives of residents, family, and staff. Gerontologist. 2012;52(1):56-65.

29. Gomez-Gallego M, Gomez-Amor J, Gomez-Garcia J. Determinants of quality of life in Alzheimer's disease: perspective of patients, informal caregivers, and professional caregivers. Int Psychogeriatr. 2012;24(11):1805-15.

30. Graske J, Fischer T, Kuhlmey A, Wolf-Ostermann K. Quality of life in dementia care--differences in quality of life measurements performed by residents with dementia and by nursing staff. Aging Ment Health. 2012; 16(7):819-27.
31. Moyle W, Murfield JE, Griffiths SG, Venturato L. Assessing quality of life of older people with dementia: a comparison of quantitative self-report and proxy accounts. J Adv Nurs. 2012;68(10):2237-46.

32. Sheehan BD, Lall R, Stinton C, Mitchell K, Gage H, Holland C, Katz J. Patient and proxy measurement of quality of life among general hospital inpatients with dementia. Aging Ment Health. 2012;16(5):603-7.

33. Zhao H, Novella JL, Drame M, Mahmoudi R, Barbe C, di Pollina L, Aquino JP, Pfitzenmeyer P, Rouaud O, George MY, Ankri J, Blanchard F, Jolly D. Factors associated with caregivers' underestimation of quality of life in patients with Alzheimer's disease. Dement Geriatr Cogn Disord. 2012;33(1):11-7.

34. Arons AM, Krabbe PF, Scholzel-Dorenbos CJ, van der Wilt GJ, Rikkert MG. Quality of life in dementia: a study on proxy bias. BMC Med Res Methodol. 2013:13:110.

35. Yeaman PA, Kim DY, Alexander JL, Ewing H, Kim KY. Relationship of physical and functional independence and perceived quality of life of veteran patients with Alzheimer disease. Am J Hosp Palliat Care. 2013;30(5):462-6.

36. Zucchella C, Bartolo M, Bernini S, Picascia M, Sinforiani E. Quality of life in Alzheimer disease: a comparison of patients' and caregivers' points of view. Alzheimer Dis Assoc Disord. 2014;29(1):50-54.

37. Williams LS, Bakas T, Brizendine E, Plue L, Tu W, Hendrie H, Kroenke K. How valid are family proxy assessments of stroke patients' health-related quality of life? Stroke. 2006:37(8):2081-5.

38. Whynes DK, Sprigg N, Selby J, Berge E, Bath PM. Testing for differential item functioning within the EQ-5D. Med Decis Mak. 2013;33(2):252-60.

39. Hilari K, Owen S, Farrelly SJ. Proxy and self-report agreement on the stroke and aphasia quality of life scale-39. J Neurol Neurosurg Psychiatry. 2007; 78(10):1072-5.

40. Zimmermann F, Endermann M. Self-proxy agreement and correlates of health-related quality of life in young adults with epilepsy and mild intellectual disabilities. Epilepsy Behav. 2008;13(1):202-11.

41. Schmidt S, Power M, Green A, Lucas-Carrasco R, Eser E, Dragomirecka E, Fleck M. Self and proxy rating of quality of life in adults with intellectual disabilities: results from the DISQOL study. Res Dev Disabil. 2010;31(5):1015-26.

42. Hung SY, Pickard AS, Witt WP, Lambert BL. Pain and depression in caregivers affected their perception of pain in stroke patients. J Clin Epidemiol. 2007;60(9):963-70.

43. McPhail S, Beller E, Haines T. Two perspectives of proxy reporting of healthrelated quality of life using the Euroqol-5D, an investigation of agreement. Med Care. 2008:46(11):1140-8.

44. Pickard AS, Lin HW, Knight SJ, Sharifi R, Wu Z, Hung SY, Witt WP, Chang CH, Bennett CL. Proxy assessment of health-related quality of life in African American and white respondents with prostate cancer: perspective matters. Med Care. 2009:47(2):176-83

45. Pickard AS, Knight SJ. Proxy evaluation of health-related quality of life: a conceptual framework for understanding multiple proxy perspectives. Med Care. 2005:43(5):493-9.

46. Smith N, Malley J. Understanding and addressing underrepresentation in a postal survey of social care users. Canterbury: QORU, University of Kent; 2012

47. Ritchie J, Lewis J, McNaughton Nicholls C, Ormston R. Qualitative research in practice: a guide for social science students and researchers. London: Sage; 2014

48. Krueger RA. Focus groups: a practical guide for applied research. London: Sage; 2000.

49. Gale NK, Heath G, Cameron E, Rashid S, Redwood S. Using the framework method for the analysis of qualitative data in multi-disciplinary health research. BMC Med Res Methodol. 2013;13:117.

50. Rand S, Caiels J. Using proxies to assess quality of life: a review of the issues and challenges. Canterbury: QORU, University of Kent; 2015.

51. Rand S, Caiels J, Collins G, Forder J. Developing a proxy-report version of the Adult Social Care Outcome Toolkit (ASCOT). Health Qual Life Outcomes. 2017;15:108.

52. Bryan S, Hardyman W, Bentham P, Buckley A, Laight A. Proxy completion of EQ-5D in patients with dementia. Qual Life Res. 2005;14(1):107-18.

53. Elliott D, Lazarus R, Leeder SR. Proxy respondents reliably assessed the quality of life of elective cardiac surgery patients. J Clin Epidemiol. 2006; 59(2):153-9.

54. Fleming A, Cook KF, Nelson ND, Lai EC. Proxy reports in Parkinson's disease: caregiver and patient self-reports of quality of life and physical activity. Mov Disord. 2005;20(11):1462-8

55. Hung MC, Yan YH, Fan PS, Lin MS, Chen CR, Kuo LC, Yu CJ, Yao G, Hsieh CL, Wang JD. Measurement of quality of life using EQ-5D in patients on prolonged mechanical ventilation: comparison of patients, family caregivers, and nurses. Qual Life Res. 2010;19(5):721-7. 
56. Jones CA, Feeny DH. Agreement between patient and proxy responses of health-related quality of life after hip fracture. J Am Geriatr Soc. 2005;53(7): 1227-33.

57. Tripoliti E, Campbell C, Pring T, Taylor-Goh S. Quality of life in multiple sclerosis: should clinicians trust proxy ratings? Mult Scler. 2007;13(9):1190-4.

58. Hounsome N, Orrell M, Edwards RT. EQ-5D as a quality of life measure in people with dementia and their carers: evidence and key issues. Value Health. 2011;14(2):390-9.

59. Becchi A, Rucci P, Placentino A, Neri G, de Girolamo G. Quality of life in patients with schizophrenia--comparison of self-report and proxy assessments. Soc Psychiatry Psychiatr Epidemiol. 2004;39(5):397-401.

60. Gil Z, Abergel A, Spektor S, Khafif A, Fliss DM. Patient, caregiver, and surgeon perceptions of quality of life following anterior skull base surgery. Arch Otolaryngol Head Neck Surg. 2004;130(11):1276-81.

61. Jones JM, McPherson CJ, Zimmermann C, Rodin G, Le LW, Cohen SR. Assessing agreement between terminally ill cancer patients' reports of their quality of life and family caregiver and palliative care physician proxy ratings. J Pain Symptom Manag. 2011;42(3):354-65.

62. Makai P, Brouwer WB, Koopmanschap MA, Nieboer AP. Capabilities and quality of life in Dutch psycho-geriatric nursing homes: an exploratory study using a proxy version of the ICECAP-O. Qual Life Res. 2012;21(5):801-12.

63. NHS Digital. (2015). Personal social services adult social care survey, England - 2014-15. From http://content.digital.nhs.uk/catalogue/PUB18642

64. Dinglas VD, Gifford JM, Husain N, Colantuoni E, Needham DM. Quality of life before intensive care using EQ-5D: patient versus proxy responses. Crit Care Med. 2013:41(1):9-14.

65. Ramos-Remus C, Castillo-Ortiz JD, Sandoval-Castro C, Paez-Agraz F, SanchezOrtiz A, Aceves-Avila FJ. Divergent perceptions in health-related quality of life between family members and patients with rheumatoid arthritis, systemic lupus erythematosus, and ankylosing spondylitis. Rheumatol Int. 2014;34:1743.

66. Ferri $\mathrm{CV}$, Pruchno RA. Quality of life in end-stage renal disease patients: differences in patient and spouse perceptions. Aging Ment Health. 2009; 13(5):706-14.

67. Gabbe BJ, Lyons RA, Sutherland AM, Hart MJ, Cameron PA. Level of agreement between patient and proxy responses to the EQ-5D health questionnaire 12 months after injury. J Trauma Acute Care Surg. 2012;72(4):1102-5.

68. Beadle-Brown J, Murphy G, Di TM. Quality of life for the Camberwell cohort. J Appl Res Intellect Disabil. 2009:22(4):380-90.

69. Schiffczyk C, Jonas C, Lahmeyer C, Muller F, Riepe MW. Gender-dependence of substituted judgment on quality of life in patients with dementia. BMC Neurol. 2011;11:118

Ready to submit your research? Choose BMC and benefit from:

- fast, convenient online submission

- thorough peer review by experienced researchers in your field

- rapid publication on acceptance

- support for research data, including large and complex data types

- gold Open Access which fosters wider collaboration and increased citations

- maximum visibility for your research: over $100 \mathrm{M}$ website views per year

At $\mathrm{BMC}$, research is always in progress.

Learn more biomedcentral.com/submissions 